\title{
Flipped Teaching of English Linguistics as an Innovation in Theoretical Class of Universities
}

\author{
Shiyong Jiang \\ School of Foreign Languages, Leshan Normal University, 778\#, Binhe Road, Shizhong district, \\ Leshan, Sichuan Province, 614000, China \\ jsyenglish@126.com
}

Keywords: Flipped teaching; Innovation; English linguistics; Theoretical class; Strategies

\begin{abstract}
Theoretical course is the necessary element of college courses which helps students understand important concepts, ideas and theories of certain discipline. However, being abstract and difficult in nature, theoretical classes have become a hard nut for both teachers and students to crack. Currently, with the development of technology, flipped teaching has become a popular trend. This paper, with English linguistics as an example, explores how flipped learning can be carried out in a theoretical class as an innovation and provides strategies for both the teacher and students in the flipped classroom
\end{abstract}

\section{Introduction}

Theoretical class is a prominent component of college courses of humanities and arts. For many of the students in China, especially for English majors, theoretical class seems to be somewhat boring and useless. Many students complain that theoretical classes, such as linguistics, lexicology and so on are difficult to learn on one hand, and meaningless on the other hand. They wonder why they should have such classes which cannot help them in job hunting in the future. It is clear that theoretical class itself is not problematic, but the way how it is lectured is to be criticized as argued by researchers and students. In the era of learning with internet, knowledge is no longer the only advantage of the teacher, so changes must be brought to the teaching of theoretical class. In recent years, with the development of internet and computer technology, flipped teaching has become a popular trend of reform in higher education. Basically, the concept of flipped teaching is that students should be given more freedom in learning before class and more time can be spent on those significant issues like solving students' doubts, application of knowledge. This idea, although not completely mature, can surely shed some light on the reform of theoretical class. This paper aims to probe into the theory and practice of flipped teaching in theoretical class with linguistics as the example, so as to provide references for the innovation of theoretical class in university.

\section{Problems of Linguistics as a Theoretical Course}

In the cultivation program of English majors, there are courses aiming at knowledge and abilities, among which, linguistics is the one to guide students learning the linguistic knowledge. However, in many universities, there are some common problems all teachers have to deal with.

Lack of Experience of Language System. Generally, the course of linguistics is set in Grade three, and a common problem is that students do not have any idea or experience of linguistics. They only learn English language through the courses like intensive reading, extensive reading, writing, grammar, and so on. Therefore, many students may feel puzzled at the course of linguistics. They wonder what the function of the course is, and how it can be learnt. Because of this, they feel at a loss of the contents which may seem to be somewhat abstract.

Lack of Motivation in Learning Linguistics. For English majors, they regard the mastery of the language as their primary target. Anything that is not directly related to the use of the language would be viewed as meaningless. However, this may not be criticized because of the orientation of universities since the majority of Chinese students give priority to jobs rather than the improvement of personal quality. All is said, it's natural to find that students do not have high motivation in 
learning linguistics. They fail to understand that linguistics is quite helpful in mastering the language as whole.

Being Abstract in Nature. Another problem of linguistics class is that the course itself tends to be theoretical in nature because it deals with the study of language system, such as phonology, semantics, syntax and pragmatics. This course is different from other courses like advanced English, English reading, etc. To study language, more meta-knowledge is required, that is, students have to think about the system, such as phonological system, morphological system, syntactic system, which are almost abstract for students and make learning very difficult. In the course book, there are many terminologies like synchronic, diachronic, langue, parole, complement, etc. Many students find it to be difficult and lose their confidence in their learning. As a result, a bad habit of waiting for the teacher to explain the knowledge is thus formed gradually. If there is no effective teaching method, design or if the teacher cannot teach effectively, linguistics will become a hard nut to crack or even worse.

\section{The Calling for Flipped Teaching in Linguistics}

The problems of linguistics indicate one single fact, that is, due to the abstract feature of the course itself, students may lose their initiatives of learning. Understanding this, we need to try to find out a useful teaching model or teaching method suitable for the very course. Then, there comes a calling for autonomous learning and students' own responsibility in the practice.

Therefore, flipped teaching, as adopted by many teachers is becoming a necessity in teaching linguistics. The flipped classroom is a new pedagogical model in which the typical lecture and homework elements of a course are reversed. For example, Ojalvo described the flipped classroom as an inverted classroom that aims to fix the traditional lecture model of instruction [1]. This approach has been adopted in a wide range these days as more and more teachers and schools are implementing its ideology in their teaching.

A typical feature of flipped classroom is that the order of teaching and learning are reversed, for example, short video lectures are viewed by students before the class session, while in-class time is devoted to exercises, discussions or projects [2]. The notion of a flipped classroom draws on such concepts as active learning, student engagement, hybrid or blended learning. According to some researchers, students prefer to have flipped class because deep interaction between the teacher and students is increased [3]. This is more valuable than the traditional one characterized by monologue lecturing. Currently, the trend of flipped class has a great influence across the world. In tertiary education domain, it is more feasible in that students are more capable of carrying out autonomous learning.

\section{Practical Strategies of Flipped Teaching in Linguistics Course}

The flipped teaching and learning is a new concept for Chinese teachers. To carry out a flipped class, both the teacher and student must cooperate in a harmonious way. In doing so, both the teacher's and students" concepts of "flipping", activities before, in and after class must be organized in a systematic way. In our practice, the following strategies were adopted, which were proofed to be effective:

Forming the Concepts of Flipped Teaching. Introducing a flipped class is often a radical enough innovation that some may be hesitant to alter an existing grading system [4]. In our practice, first of all, both the teacher and students are required to change the traditional idea of teaching and learning to make it "flipped", that is, the roles of the teacher and students, as well as the environment of learning, ways of teaching will all be flipped. Learning will happen first before class, and the class is used for discussion, creation and solving problems. However, this is not an easy task since ideology is always a tough issue and cannot be changed without efforts. In our experiment, the teacher has read and learnt a lot about flipped teaching and tried to "force" himself to try the new method with efforts. This is a continuous process lasting a whole term of schooling. Then, it was even more difficult to change students' idea although they were excited at the very 
beginning. Keeping students motivated throughout the whole duration of the experiment was one of the worrying problems. In our case, we carried out many interviews and small talks with students, giving them encouragement, praise, carrying out competition among students. It is through such a way that students were motivated to build the concept of flipped learning gradually.

Making a Good Design with the Cooperation of Students. To have an effective flipped class, both the linguistics teacher and students are supposed to cooperate to make a good design which functions as the road map for the action in the following sessions. In our example, with the formation of the concept of flipped teaching and learning, students were more informed of how to learn and what to learn, constructing the base of flipped learning and teaching. Based on that, the teacher designed a whole unified teaching plan accordingly. In this design, characteristics of the tradition, the reality of students, teaching model, teaching activity and evaluation were all taken into good consideration. In doing so, students were negotiated and their ideas, their voices were examined carefully. Through such actions, students can all be involved in the framework of flipped teaching since they are more aware of their own responsibilities and opportunities indirectly [5]. In our case, all the students were required to set their own learning goals with their expected future profession, such as translation, teaching or business. As expected, they brought this plan in their learning process effectively.

Carrying out Effective Pre-class Learning Effectively. When the design is set for the teaching, the most important step in flipped teaching is to carry out teaching in an effective way. According to the theory of flipped teaching, there are three sections in the teaching: pre-teaching, in-teaching and post-teaching. As argued by many researchers and teachers, the flipped classroom is to provide teaching video or other material to students for their learning before class. Before class, we provide many micro-classes made by video, audio, PPT and other materials of each chapter with the specially set questions for students' reference. Through their mobile devices like cell phones or pads, or sometimes computers, students could easily get the material and learn by themselves.

For example, in Chapter one, we divided the introduction to language into 5 parts: introduction to language as a whole, introduction to the definition of language, the features of language, the functions of language with each part lasts from 5 minutes to 10 minutes. Students are required to answer the prescribed questions while watching the video. In such a manner, students would have more freedom through watching or rewinding the contents. This is better than the traditional classroom in which students often try to capture what is being said at the instant the teacher makes the presentation and cannot come back even though they may fail in the learning. Then their understanding of the knowledge, their problems will be brought to class for further discussion.

Organizing the in-class Teaching Efficiently. In the classroom teaching session, students bring their understanding, their problems to the class for further information and the teacher is responsible to organize the class according to students' understanding, problems and expectations in their professional development. This will be handled before class by using the instant communication media like Weixin, MSN, QQ or other means in a blended way. The teacher will categorize all the questions, understand how much students have learnt the knowledge and teach accordingly. For example, in Chapter one, many students felt puzzled in understanding the distinction between Langue and Parole, between competence and performance. Therefore, in the class, we then provided more examples and give more detailed exemplification which directly improved their comprehension. This was proofed to be effective since the whole class understood it. Furthermore, more examples were given and more cases were used in helping students combine linguistic knowledge with their possible profession. In the meantime, some challenging tasks such as "Investigate how people use language in Sichuan", "Find answers to why animals do not have a similar language system like humans" were provided as post-class assignments.

Finishing the Post-class Activities in a Creative Way. After class, team work or individual work after class becomes indispensable for students to consolidate knowledge and develop critical and creative thinking. The essence of the flipped teaching is to arouse students' interest, inspire them to be self-responsible in their learning with the teacher's guide as the base. After the knowledge is mastered through the two stages, students must think and reflect on the system of 
knowledge, considering its range, value and the framework in some practical ways. Therefore, it's quite significant that some creative work be assigned to students so that they can use, reflect and reconstruct their knowledge in the process of finishing the post-class work either in group or by individuals. For example, we in our experiment asked students to solve the following problems: how do people communicate in business negotiation? And what useful strategies of vocabulary learning can be provided for middle school students? Then students were required to set goals, decide roles and each should contribute to the team work, and finally, each group made a report to share their ideas with other groups. In this stage, necessary aid must be offered through the on-line web or mobile platform. Finally, a comment was given by the teacher with a careful consideration of student's own suggestions and voices. Through such a process of analysis and problem solving, students can not only consolidate the knowledge, but also form their critical and creative thinking in a systematic way.

\section{Conclusion}

In this long history of English linguistics teaching, many teachers find it to be a difficult one for many reasons. To make the teaching more effective, it's necessary to have some innovation in teaching method and model. The current trend of flipped teaching no doubt provides some valuable insights for linguistics teaching as a theoretical course in university, which emphasizes the flipped roles and order of teaching. Through reforms as what we have done with the support of the technology, students will have more freedom and responsibilities in organizing their own learning outside the classroom, and more practical issues can be dealt with in class. This makes students feel more interested in the course, and the practical value of this course is increased significantly. Of course, there are also many difficulties in the implementation of the teaching method, such as students' resistance in autonomous learning, frustrations in team work, or complain for heavy learning burden. However, it is proofed that the problems can be solved through the joint efforts of the teacher and students. This research is exploratory and limited, it is hoped that more work with sufficient details can be done in the research of linguistic teaching in university.

\section{Acknowledgements}

In this article, the research is supported by the Project of Education and Teaching Reform of Leshan Normal University (Project number: JG2015-YB08)

\section{References}

[1] H. E., Ojalvo, \& S., Doyne. Five ways to flip your classroom with The New York Times, 2011,http://learning.blogs.nytimes.com/2011/12/08/five-ways-to-flip-your-classroom-with-thenew-yorktimes/The Flipped Classroom. https://teaching.unsw.edu.au/flipped-classroom

[2] M. J., Lage\&G., J., Platt. Inverting the classroom: A gateway to creating an inclusive learning environment. The Journal of Economic Education, Vol. 31, 2000, No.1, Pp30-43.

[3] J. Bergmann \& S., Aaron. Flip Your Classroom: Reach Every Student in Every Class Every Day. Washington: ISTE \& ASCD, 2012.

[4] N., Eydelman. A blended English as a Foreign Language academic writing course, in B., Tomlinson \&C., Whittaker. Blended Learning in English Language Teaching: Course Design and Implementation, Pp.43-50., London: British Council, 2013. 